\title{
HISTORIA Y FICCIÓN: LA CORONA DE PERLAS DE PILAR SINUÉS
}

\author{
$M^{\mathrm{a}}$. De Los Ángeles Ayala \\ Universidad de Alicante
}

\begin{abstract}
RESUMEN
En el presente artículo se analiza la novela histórica La corona de perlas (1857) de Pilar Sinués de Marco (1835-1893), resaltando sus características más peculiares y relevantes: fuentes, datos históricos, elementos folletinescos y principales recursos utilizados por la escritora.

Palabras Clave: Sinués, novela histórica, siglo XIX, La corona de perlas.
\end{abstract}

\section{Abstract}

This article analyzes the historical novel La corona de perlas (1857) by Pilar Sinués de Marco (1835-1893), highlighting its most peculiar and relevant characteristics: sources, historical data, folletinesque elements and main resources used by the writer.

KEY wORDS: Sinués, historical novel, 19th century, La corona de perlas.

Sin duda, la aparición de La Gaviota de Fernán Caballero en las páginas de El Heraldo en 1849 marca uno de los puntos álgidos en el lento camino de la incorporación de la mujer al ámbito literario español, pues su publicación tuvo la virtud de evidenciar ante lectores, escritores y críticos de su generación la capacidad de la misma para el género narrativo. La Gaviota, ensalzada por la crítica y traducida a varios idiomas, ofrece para los estudiosos del desarrollo del género al mediar el siglo XIX datos de indudable interés, pues con independencia de su valor estético, cuestión perfectamente establecida y matizada por la crítica coetánea y posterior, hallamos lo que se puede considerar el primer manifiesto del realismo español, escrito por una autora que se propone, ni más ni menos, tal como es notorio, la gran tarea de crear la novela nacional a partir de la observación minuciosa del pueblo español, alejándose, por tanto, de la influencia ejercida, especialmente, por la literatura francesa. Una cuestión sumamente 
relevante también es la reflexión que Cecilia Böhl de Faber realiza sobre la novela de costumbres, la realista, al insinuar que esta es la que más se adecua a la personalidad de la mujer. Recordemos no solo el prólogo, en el que se ponen las bases del relato realista, sino también ese juego metaliterario que la autora introduce en el capítulo XIX de $\mathrm{La}$ Gaviota, cuando un grupo de contertulios se propone escribir a modo de diversión una novela. A través de esta conversación, Cecilia Böhl de Faber va desechando elementos y géneros que no le parecen adecuados, tales como inclusión de seducciones, adulterios o suicidios, elementos propios de las novelas folletinescas de origen francés y que están en contra de su propia posición ideológica. De igual forma tampoco le parece idónea la novela lúgubre, la fantástica o la sentimental. A tenor de la información que encontramos en estos fragmentos metaliterarios se observa que la novelista esboza también la modalidad narrativa que le parece más propia para la mujer, pues fiel a su propia ideología conservadora, Cecilia Bölh de Faber no pensó en un principio competir con los escritores de su tiempo, sino que fueron las adversas circunstancias económicas que rodearon su tercer matrimonio las que la indujeron a publicar su producción literaria, mientras que ella hasta el momento se había conformado con escribir por propia satisfacción, sin contemplar la posibilidad de convertir la escritura en una actividad profesional. Ello se evidencia de manera rotunda cuando uno de los contertulios pronuncia la siguiente frase: «Escribiremos como cantan los pájaros, por el gusto de cantar; y no por el gusto de que nos oigan $»^{1}$. Esta idea se convertirá con el correr del tiempo en uno de los tópicos más característicos al que recurren las escritoras de las décadas centrales del siglo XIX para congraciarse y disipar la aversión que entre los varones despierta la práctica literaria femenina².

Fernán Caballero destaca en estas páginas, en las que se esboza una panorámica sobre las distintas formas de novelar del momento, dos fórmulas que le parecen adecuadas a la altura de 1849. Así, uno de los personajes, una condesa, señala lo siguiente: «Hay dos géneros que, a mi corto entender, nos convienen: la novela histórica, que dejaremos a los escritores sabios, y la novela de costumbres, que es justamente la que nos peta a los medio cucharas» ${ }^{3}$. La escritora parece vincular novela histórica a la práctica masculina dada la mayor preparación y conocimientos de los escritores

\footnotetext{
${ }^{1}$ C. Bölh de Faber, La Gaviota, E. Rubio (ed.), Madrid, Espasa Calpe, 1991, p. 264.

${ }^{2}$ Las escritoras recurrieron a subrayar el carácter innato, espontáneo, de su producción literaria, especialmente en el campo de la poesía, para disipar, tal como hemos señalado, la hostilidad masculina a la incorporación de la mujer al mundo de la literatura. Carolina Coronado, Gertrudis Gómez de Avellaneda o Rosalía de Castro, por citar algunas de las escritoras que más relieve alcanzaron, nos ofrecen muestras de ello. Solo como botón de muestra, recordar los conocidos versos de Gertrudis Gómez de Avellaneda: «Canto como canta el ave, / canto porque el Cielo plugo / darme el astro que me anima / como dio brillo a los astros / como dio al orbe armonía» (G. Gómez de Avellaneda, «Romance contestando a otro de una señorita», en Obras, J. M. Castro y Calvo [ed.], Madrid, Atlas, 1974, I, p. 299).

${ }^{3}$ G. Gómez de Avellaneda, La Gaviota, ob. cit., p. 268.
} 
para llevar acabo la consabida recreación histórica, mientras que la basada en la mera observación le parece más adecuada para desarrollarla las escritoras, sobre todo si en ellas la exaltación patriótica y el mensaje didáctico llega de forma nítida a los lectores como lo hace en La Gaviota.

Es evidente que el mensaje de Fernán Caballero no caló entre sus contemporáneas, pues la novela histórica escrita por mujeres ${ }^{4}$, apenas perceptible en los primeros treinta años del siglo, como sucede también en la de autoría masculina ${ }^{5}$, se desarrolló de forma notable durante estas décadas centrales de siglo. Las escritoras parecen decididas a no restringir su creación a unas modalidades que según la opinión pública les eran propicias, sino que se lanzan a explorar también aquellos géneros propiamente masculinos. Recordemos sin ánimo de ser exhaustivos, y circunscritos al ámbito de la novela histórica, la publicación de Espatolino (1844), Guatimozín, el último emperador de México (1846), Dolores (1851), Una anécdota en la vida de Cortés (1877), de Gertrudis Gómez de Avellaneda, Raimunda o la discípula de Juan de Alfa (1845), de Encarnación Calero de los Ríos, Juana de Arco. Novela histórica (1850-1851) de Ana María, El testamento de Juan I, de Teresa Arróniz, Otros tiempos, de Felicia Auber, La casa de Rocaforte (1859, $2^{\mathrm{a}}$ ed.) y Rugier de Lauriga (1859, $3^{\text {a }}$ ed.), de Felicitas Asín de Carrillo, Elena de Mendoza (1859), de Francisca de Riego y Pica, entre otras. Las novelas históricas de autoría femenina se mantienen en décadas posteriores gracias a las plumas de Faustina Sáez de Melgar,

\footnotetext{
${ }^{4}$ Recordemos que durante los treinta primeros años de siglo solo se publican en España cuatro novelas históricas de autoría femenina, tres de ellas traducciones del francés -Zulima, obra traducida por Micaela Nesbitt y Calleja (1817), Reynaldo y Elina o la sacerdotisa peruana, traducción de Antonia Tovar y Salcedo (1820), La invención del órgano o Abassa y Bermicides (1833), relato vertido al español por Maria Bellouminiy una novela original debida a la murciana Casilda Cañas de Cervantes -La española misteriosa (1833)(H. Establier, «La novela histórica escrita por las mujeres en los albores del Romanticismo. 1814-1833: creación original y adaptación de la literatura francesa en España», RILCE, 31, 1 [2015], pp. 171-199). En La española misteriosa se relata, a diferencia de los modelos de Walter Scott, hechos históricos que sucedieron un cuarto de siglo antes de que se escribiera la mencionada novela. La crítica ha valorado en términos generales la capacidad literaria de su autora, pues la novela carece de interés argumental y los diálogos adolecen de una gran artificiosidad. E. A. Peers, Historia del movimiento del romántico español, Madrid, Gredos, 1973 (2ºd.), I, p. 193, J. I. Ferreras, Los orígenes de la novela decimonónica, 1800-1830, Madrid, Taurus, 1973, pp. 303-304.

${ }^{5}$ Las traducciones de Walter Scott y la creación de las colecciones de novelas históricas propiciadas por los avispados editores Cabrerizo, Repullés, Delgado y Bergnes despertaron enorme interés entre los lectores y, sobre todo, entre los escritores que motivados por generosas remuneraciones orientaron su creación hacia la novela histórica. El caso más conocido es el de Espronceda que recibió seis mil reales por su Sancho Saldaña (E. Rubio Cremades, «La novela histórica», en Historia de la literatura española. Siglo XIX [I], Madrid, Espasa Calpe, 1996, pp. 610-642). Las primeras novelas de autor masculino se debieron a los exiliados españoles en Inglaterra, tal como sería el caso de Telesforo de Trueba y Cossío que escribió en 1828 Gómez Arias The Castilian en inglés y se tradujo al castellano en 1831, o de Ramiro, conde de Lucena (1823) de R. de Húmara y Salamanca, traducida al castellano bastantes años más tarde, en 1845 . No obstante el lapso temporal que abarca desde el fallecimiento de Fernando vII a la publicación de El señor de Bembibre (1844) de E. Gil y Carrasco, es el periodo de máximo florecimiento, pues en este aparecen las novelas debidas a López Soler, Kotska Vayo y Lamarca, Larra, Espronceda, Cortada y Sala, Escosura, Ochoa, García Villalta, Martínez de la Rosa, Estébanez Calderón, entre otros muchos. E. A. Peers, ob. cit.
} 
Eduarda Feijoo, Emilia Serrano de Tornel, Matilde Cherner, etc ${ }^{6}$.

Pilar Sinués es, de las escritoras incluidas en el canon isabelino, la que contribuyó en mayor medida al desarrollo de la ficción de carácter histórico ${ }^{7}$. A esta escritora zaragozana le debemos Luz de luna. Leyenda histórica del siglo XV $(1855)^{8}$, El Ángel de la Muerte (leyenda histórica) (1855) ${ }^{9}$, Las dos sultanas. Leyenda árabe (1855) ${ }^{10}$, La diadema de perlas. Novela histórica original (1857), La princesa de los Caspios (1857) ${ }^{11}$, La corona de sangre $(1857)^{12}$, La hermana de Velázquez $(1857)^{13}$, iPobre Ana!! Leyenda histórica $(1861)^{14}$, Dos venganzas. Novela histórica $(1862)^{15}$, Dona Urraca Queen of Leon and Castile. An historical romance of de Middle Ages $(1890)^{16}$. De todas ellas, dada la naturaleza del

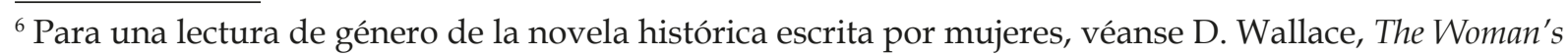
Historical Novel, Houndmills, Basingstoke, Palgrave Macmillan, 2005; J. Wallach Scott, Género e historia, México, FCE y Universidad Autónoma de la Ciudad de México, 2008; H. Establier, «Historia, ideología y perspectiva de género en la España del siglo XIX: el "ciclo" de leyendas históricas de María del Pilar Sinués de Marco (1855-1857)», Hispanófila (en prensa).

${ }^{7}$ Los estudios críticos sobre la obra literaria de Pilar Sinués son escasos. Destacamos, entre otros, los siguientes: A. González Sanz, «El uso de la historia en la poesía romántica femenina: el caso de María del Pilar Sinués (1835-1893)», en S. Boadas, F. E. Chávez y D. García Vicens (coords.), La tinta en la clepsidra: fuentes, historia y tradición en la literatura hispánica, Barcelona, PPU, 2012, pp. 223-230 y «Domesticar la escritura. Profesionalización y moral burguesa en la obra pedagógica de P. Sinués (1835-1893)», Revista de Escritoras Ibéricas, 1 (2013), pp. 223-230; H. Establier, «Historia, ideología y perspectiva de género», art. cit.; S. Hibbs-Lissorgues, «Escritoras españolas entre el deber y el deseo: Faustina Sáez de Melgar (1834-1895), Pilar Sinués de Marco (1835-1893) y Antonia Rodríguez de Ureta», en P. Fernández y M. L. Ortega (eds.), La mujer de letras o la "letraherida": discursos y representaciones sobre la mujer escritora en el siglo XIX, Madrid, CSIC, 2008, pp. 325-343; L. Romero Tobar, «María Pilar Sinués, de la provincia a la capital del reino», Arbor, 190-767 (mayo-junio 2014), pp. 1-9; I. Sánchez Llama, «El 'varonil' realismo y la cultura oficial de la Restauración en el fin de siglo peninsular: el caso de María Pilar Sinués de Marco (1835-1893)», Letras Peninsulares, 12, 1 (1999), pp. 37-64; «María Pilar Sinués de Marco y la cultura oficial peninsular del siglo XIX: del neocatolicismo a la estética realista», Revista Canadiense de Estudios Hispánicos, XXIII, 2 (1999), pp. 271-288; Galería de escritoras isabelinas. La prensa periódica entre 1833 y 1895, Madrid, Cátedra, 2000 y Antología de la prensa periódica isabelina escrita por mujeres, Cádiz, Universidad, 2001.

${ }^{8}$ Luz de luna se publicó en la Revista Española de Ambos Mundos, tomo III (1855), pp. 634-661; Reproducida en volumen suelto, Luz de luna. Leyenda histórica del siglo xv, Zaragoza, Imprenta de Ramón León, 1855 e incluida en su colección Amor y llanto. Colección de novelas históricas originales, Madrid, Imprenta de T. Núñez Amor, 1857, pp. 209-257.

${ }^{9}$ Este relato en verso se encuentra incluido en su obra Cantos de mi lira. Colección de leyendas en verso, Madrid, Imprenta de Tomás Núñez Amor, 1857, pp. 17-111.

${ }^{10} \mathrm{Al}$ igual que el anterior, Las dos sultanas se encuentra inserto en Cantos de mi lira, ob. cit., pp. 181-259.

${ }^{11}$ Relato incluido en su volumen titulado Amor y llanto, ob. cit., pp. 261-307.

${ }^{12}$ Como en el caso anterior, La corona de sangre se publicó dentro de la colección Amor y llanto, ob. cit., pp. 5-90.

${ }^{13}$ La hermana de Velázquez, en Amor y Llanto, ob. cit., pp. 313-421.

${ }^{14}$ iiPobre Ana!! Leyenda histórica, Madrid, Imprenta de Juan Antonio García, 1861.

${ }^{15}$ Dos venganzas. Novela histórica, Madrid, Imprenta Española, 1862.

${ }^{16}$ Dona Urraca Queen of Leon and Castile. An historical romance of the Middle Ages. Traslated fron Spanish by Reginal Huth, Bath, Wilkinson Bros., 1890. C. Simón Palmer, «Pilar Sinués», en Escritoras españolas del siglo xIX. Manual bio-bibliográfico, Madrid, Castalia, 1991, pp. 650-671. 
monográfico, centraremos nuestro análisis en La diadema de perlas por situarse la acción en tiempos del primer rey de la casa de Trastámara, Enrique II, que reinará en Castilla tras la guerra civil que se desarrolló en tiempos de su hermano Pedro i y que, como es notorio, concluyó con el asesinato del mismo en 1369, en lo que algunos historiadores han denominado «la primera guerra civil española» ${ }^{17}$. No obstante, cabe mencionar también, aunque no se analicen en el presente trabajo, otros dos relatos que por su temática se aproximan al objeto de este trabajo, La diadema de perlas. Me refiero a su leyenda en verso El Ángel de la Muerte, pues en ella se recrean las disputas entre los dos hermanastros, y Luz de luna, donde Pilar Sinúes nos introduce en el tiempo de Enrique IV, aunque la ficción amorosa desbanque por completo la reconstrucción histórica.

La diadema de perlas, a pesar de su subtítulo, novela histórica, es una narración breve, gira en torno a unas cien páginas, número singularmente escaso a tenor de los voluminosos tomos que configuran la mayor parte de las novelas históricas tanto del periodo anterior como del posterior. A pesar de esta evidente brevedad, Pilar Sinués divide su obra en dos partes, la primera titulada significativamente, dado el objetivo de enmarcar la historia, con el marbete «Los bastardos de Alonso Onceno», mientras que la segunda, denominada «El mártir de corazón», nos sitúa en el drama amoroso. La diadema de perlas, publicada en 1857, se enmarca en ese periodo en que la novela de reconstrucción arqueológica, erudita, propia de las genuinamente románticas, va perdiendo la minuciosa fidelidad de los datos para asimilar elementos de procedencia folletinesca, de ahí que se observe en su composición una discriminada selección de datos históricos en función de la justificación de la asombrosa ficción amorosa que la escritora ofrece. La novela se abre con la mención a Enrique II, quien «después de haber clavado su daga en el pecho de su hermano Pedro en los campos de Montiel» ${ }^{18}$, se encuentra en Burgos celebrando su victoria, a punto de trasladarse a Sevilla con el objeto de convocar cortes. Estos son los únicos datos con los que el lector cuenta, pues en los párrafos siguientes el protagonismo lo adquiere un misterioso personaje que, embozado y de forma cautelosa, sale por una puerta del alcázar sigilosamente para acudir a una cita amorosa. Florestán, el embozado, alcanza la humilde casa en la que habita Berenguela y tras proclamar su amor por la bella joven, le anunciará su decisión de abandonar Burgos para seguir las huestes de Enrique II en su trayecto a Sevilla, pues su honor y su conciencia le impelen a ello. La promesa de amor eterno se sella con la entrega de una corona de perlas que la madre de Florestán llevaba cuando fue vilmente asesinada y que esta le entregó amorosamente a su hijo instantes antes de fallecer.

${ }^{17} \mathrm{~J}$. Vadeón Baruque, Pedro I y Enrique de Trastamara. ¿La primera guerra civil española?, Madrid, Aguilar, 2003 y Los Trastámaras: El triunfo de una dinastía bastarda, Madrid, Temas de España, 2001.

${ }^{18}$ M. P. Sinués, La corona de perlas, ob. cit., p. 95. 
Tras un salto en el tiempo, el supuesto componente histórico vuelve a aparecer en los capítulos que configuran la primera parte de la novela gracias a la narración que realiza don Álvaro Garcés, conde de Carrión, sobre los hechos acaecidos tiempo atrás, cuando el rey Alfonso XI y Leonor de Guzmán, su amante y madre de diez de sus hijos, le confían la suerte de sus dos vástagos pequeños, Sancho y Berenguela, pues temen la ira de la reina doña María de Portugal, esposa del monarca. Es de rigor advertir que Pilar Sinués hace un uso muy deficiente del dato histórico y, aunque en líneas muy generales se mantiene fiel a la historia, esta aparece convenientemente adornada con elementos totalmente ficticios o, en ocasiones, notablemente desdibujada para exponer las pasiones humanas, tomando estas el máximo protagonismo en el relato. Tal circunstancia se evidencia ya en el inicio de estos primeros capítulos en los que la autora en principio intenta justificar históricamente su novela. Así, pues, don Álvaro Garcés, conde de Carrión, no tiene una correspondencia histórica, pues este título nobiliario fue otorgado primero por Pedro i a Sir. Hugh Calveley por la ayuda prestada en su lucha contra su hermanastro, hasta que lo perdió tras la muerte de Pedro I en la batalla de Nájera. Posteriormente, el título recayó en Juan Sánchez Manuel por su apoyo a Enrique de Trastámara en la mencionada contienda que sostuvieron los hermanastros. Esta inexactitud histórica le permite a la escritora tomarse otras licencias, pues además de convertir al conde de Carrión en el enamorado más fiel y casto de la desaparecida Leonor de Guzmán, le otorga el papel de protector de los dos últimos vástagos de Alfonso XI y doña Leonor. Por la documentación histórica sabemos que estos dos últimos descendientes fueron Sancho Alfonso (1343-1374) y Pedro Alfonso (1345-1359), mientras que Pilar Sinués presenta, por un lado a Berenguela, último fruto del apasionado amor de los reyes y, por otro, a Sancho, un personaje que al menos por su nombre se podría identificar con el Sancho Alfonso histórico, aunque la edad del mismo en la novela, «Tenía este veintidós años a lo sumo» ${ }^{19}$, no concuerde totalmente con la real.

Estamos ante unos capítulos llenos de sorpresas, en los que los personajes identificados en un primer momento con un nombre falso, adquieren su identidad verdadera. Así, el misterioso caballero que llega en el capítulo i a la humilde casa donde habita Berenguela resulta ser el mencionado conde de Carrión, quien a su vez descubrirá el origen noble de la joven. Igualmente, un misterioso caballero que se presenta como D. García y que, supuestamente, es hijo de un hidalgo de Lerma, se identifica en un primer momento como el hijo del propio conde de Carrión, D. Fernando, enamorado y sin el consuelo de ser correspondido por Berenguela. Posteriormente, cuando en una conversación en la que el joven se sincera con don Álvaro Garcés, este, lleno de pasión, confirma su amor por la joven Berenguela y su decidida determinación por

\footnotetext{
${ }^{19}$ Ibidem, p. 108.
} 
mantenerse fiel a su señora el resto de su vida — «Nada podrá hacer que yo deje de amarla y de consagrarle mi vida» ${ }^{20}-$ y por encima de los ruegos de D. Álvaro para que la olvide, indicándole con el rostro demudado por el dolor que esa joven jamás podrá ser suya — «jOlvidarla!, padre! Arrancadme el corazón con vuestra propia mano, si queréis que yo olvide a Berenguela» ${ }^{21}-$, a don Álvaro no le queda otra opción de confesarle lo siguiente:

Vos no sois mi hijo, como yo os hice creer: sois Don Sancho, el ante-último hijo del Rey Alonso onceno y de Doña Leonor de Guzmán, iy esa joven es la infanta Doña Berenguela, postrer fruto de aquellos desgraciados amores! ¡Matadme, señor repitió el anciano doblado ante el suelo su calva frente-, porque solo hundiendo en mi pecho vuestra espada, conseguiréis acercaros a ella! ${ }^{22}$

La tensión emocional sigue acrecentándose, pues en el rostro desencajado por el descubrimiento de que Berenguela y él son hermanos, se percibe una nueva inquietud, como si intuyese que el drama amoroso no ha concluido y pudiera aumentar su intensidad. El padre le confirmará su peor suposición, el caballero del que se ha enamorado Berenguela, Florestán, y por quien ha perdido la razón a raíz de su prolongada ausencia es Enrique II, rey de Castilla, el hermano de ambos. Como es evidente Pilar Sinués desplaza el interés de la acción al conflictivo asunto amoroso, dos hermanos criados al margen el uno del otro y enamorados ambos de una desconocida hermana.

En los dos últimos capítulos de esta primera parte, v y VI, se pone de manifiesto la gran habilidad de la escritora para hilvanar con suma maestría y sin dejar cabo suelto los datos históricos necesarios para dar sentido a la ficción novelesca. En ellos el conde de Carrión revela el hondo misterio que ha rodeado la vida de Sancho y Berenguela, cuando el conde, enamorado sin remisión de Leonor de Guzmán y leal al rey Alfonso XI, jura proteger a los infantes y guardar silencio sobre su identidad. El conde en su relación de los hechos se retrotrae al momento en el que Alfonso XI le encomienda con el mayor encarecimiento que salve a su hijo recién nacido, Sancho, del odio de su esposa, la reina doña María de Portugal, y lo crie secretamente, haciéndolo pasar por hijo suyo. Ocho días después del ruego el rey y Leonor de Guzmán marchan a poner cerco a Gibraltar dejando en sus manos la suerte de su hijo ${ }^{23}$, protección que de nuevo le solicita el rey al dar a luz doña Leonor una nueva infanta, ya que la pareja real había sido advertida de la existencia en el campamento de unos espías de doña María de Portugal que tenían orden de apoderarse de los bastardos. De ahí que el

\footnotetext{
${ }^{20}$ Ibidem, p. 113.

${ }^{21}$ Ibidem, p. 112.

${ }^{22}$ Ibidem, p. 113.

${ }^{23}$ Ibidem, p. 121.
} 
rey angustiado por la suerte de sus descendientes solicite de nuevo la ayuda leal del conde de Carrión: «-Sálvala, Conde- me dijo-; sálvala como a su hermano; tal vez, de entre todos mis hijos, serán los únicos que conserven la vida los dos que confío a tu cuidado» ${ }^{24}$.

Conviene subrayar que además de incluir el lugar, Gibraltar, y la fecha concreta en el que sitúa la acción, 26 de marzo de 1350, dato que nos remite a la fecha de fallecimiento de Alfonso XI víctima de la peste, Pilar Sinués reproduce un texto en el que se describe el lecho en el que el rey yace rodeado de los principales símbolos -banderas, armas y pendones- que dan fe de las victorias alcanzadas en vida, descripción que sobresale del texto literario, pues la autora utiliza la letra cursiva para destacarla del resto de la narración, incluyendo una escueta nota a pie de página en la que aparece el apellido Bolangero. Por primera vez la escritora parece indicar una fuente concreta, pues Bolangero podría remitir al desconocido autor del siglo XIX Víctor África Bolangero, autor, al menos, de tres novelas históricas que se publicaron en 1850 -Don Pedro I de Castilla o El grito de la venganza ${ }^{25}$, Fernando IV de Castilla o Dos muertos a un tiempo ${ }^{26}$ y Alfonso Onceno o quince años después ${ }^{27}$, continuación de la anterior. En todo caso, es evidente que no se trata de una fuente histórica, sino que parece tomada de otra ficción novelesca. Dada la rareza del autor y de las propias novelas, solo hemos podido comprobar que dicha descripción no se encuentra en la obra titulada Alfonso Onceno, novela que puede consultarse en la Biblioteca Virtual Miguel de Cervantes.

El conde de Carrión completa la relación de los sucesos acaecidos tras la muerte del rey Alfonso xI en Gibraltar, después de que este proclamase a Pedro i como su legítimo sucesor al trono castellano, decisión que a D. Enrique, conde de Trastámara, enoja enormemente, aunque trate de esconder sus emociones. Doña Leonor ordena trasladar el cuerpo del rey desde Gibraltar hasta Sevilla, donde se encuentra su legítima esposa y su hijo D. Pedro, mientras que envía a sus propios hijos a Algeciras, ciudad adepta a su persona, por temer las represalias de Doña María de Portugal y de su hijo, temor que se confirma, pues una vez concluidas las fiestas de proclamación del heredero al trono, doña Leonor será apresada y conducida a prisión. En acciones paralelas se

\footnotetext{
${ }^{24}$ Ibidem, p. 124.

${ }^{25}$ V. Á. Bolangero, Don Pedro I de Castilla o El grito de la venganza. Novela histórica original, Madrid, Repullés, 1850. Según Antonio Palau Dulcet, Manual del librero hispano-americano, Barcelona, Palau Dulcet, t. II, 1949, p. 307, la novela se publicó en 1850 y 1851, sin indicación de imprenta. A esta edición le siguió una nueva que resultó ser la más apreciada: Don Pedro I de Castilla o El grito de la venganza. Novela histórica original. Continuada con la historia de D. Enrique II, dando fin con la historia de don Pedro el Cruel, Madrid, 1852. También reseña una cuarta edición, Madrid, 1857.

${ }^{26}$ V. Á. Bolangero, Fernando IV de Castilla o dos muertos a un tiempo. Novela histórica del siglo XIV, Madrid, Márquez, 1850.

${ }^{27}$ V. Á. Bolangero, Alfonso el Onceno o quince años después. Novela histórica. Continuación de Fernando IV de Castilla, Madrid, Librería de Sánchez Rubio, Imprenta de Miguel G. González, 1850.
} 
describen los movimientos de los principales personajes de la historia. Pedro i se traslada a Burgos donde llevará a cabo su juramento como rey, mientras Enrique, el conde Trastámara, parte desde Algeciras hacia Asturias para alzar pendones contra el nuevo rey, Doña Leonor es enviada a la prisión de Talavera de la Reina y se confina a dos de los descendientes bastardos, D. Juan y D. Fernando, al castillo de Carmona. La venganza de la legítima esposa del rey Alfonso XI culmina en febrero de 1351 cuando llega la noticia de que los dos infantes antes mencionados, de dieciocho y catorce años de edad, respectivamente han sido vilmente degollados y doña Leonor asesinada a manos de Alonso Fernández de Olmedo por orden de doña María, instantes antes de que su hijo Enrique y el conde de Carrión llegasen a su prisión para impedir su muerte. De nuevo Pilar Sinués adapta la historia a la ficción, pues aunque no deforma el espíritu de la historia, la altera para acentuar el dramatismo de la trama novelesca y, especialmente, justificar el comportamiento de Enrique de Trastámara. La relación de los hechos se acerca a lo que encontramos en los primeros capítulos de la Crónica de Pedro I en lo que respecta a su encarcelamiento en la prisión de Sevilla, primero, y más tarde en Talavera de la Reina, donde se produce su asesinato a manos del mencionado Alfonso Fernández Olmedo, personaje que ha pasado a la historia por su cruel acción ${ }^{28}$. La escritora, como todos los libros que parten de la crónica de López de Ayala, señala en esta afrentosa acción el detonante que llevará a los hermanastros a un enfrentamiento por el poder real, arrastrando con ellos a sus respectivos partidarios ${ }^{29}$. En este sentido la escritora es fiel a las líneas generales de la historia aunque introduzca elementos que no se corresponden totalmente con la verdad histórica, bien por cambiar la secuencia temporal, alterar la presencia de personajes reales en un determinado momento o por incorporar elementos ficticios que doten al relato de los hechos un mayor dramatismo. Así, por ejemplo, en la novela de Pilar Sinués, Enrique de Trastámara está presente en el momento en que su madre está agonizando, hecho totalmente falso, pues por la historia sabemos que al único hijo que se le permitió visitar a doña Leonor de Guzmán cuando estaba presa en Talavera fue a Fadrique, Maestre de Santiago. Cabe subrayar, igualmente, la alteración temporal y de identificación de uno de los hermanastros asesinados por orden de Pedro I. En la novela los infantes Juan y Fernando son las víctimas del rencor del rey, mientras que los hermanastros que encontraron la muerte por orden de Pedro I fueron Fadrique, Maestre de Santiago, Juan Alfonso, señor de

\footnotetext{
${ }^{28}$ Véanse especialmente los capítulos IV, XII, correspondientes al primer año de reinado de D. Pedro, y el III del «Año segundo de su reinado. 1351», López de Ayala, En el nombre de Dios, amén, comienza la crónica del Rey Don Pedro, fijo del rey don Alfonso, Onceno (I) de este nombre en Castilla, en Crónicas de los Reyes de Castilla, C. Rosell (ed.), Madrid, Rivadeneyra, Editor, 1875, pp. 404, 405 y 408.

${ }^{29}$ Así lo testimonia P. López de Ayala: «[...] E desto pesó mucho á algunos del Regno; ca entendían que por tal fecho como este venían grandes guerras é escándalos en el Regno, segund fueron después, por quanto la dicha Doña Leonor avia grandes fijos é muchos parientes. É en estos fechos tales, por poca venganza, recrescen después muchos males e daños, que seria muy mejor escusarlos: ca mucho mal é mucha guerra nació en Castilla por esta razón», Crónica de Pedro I, ob. cit., p. 413.
} 
Badajoz y Pedro Alfonso, hechos violentos que se fechan en el caso del D. Fadrique en 1358 y el de los dos restantes en 1359. Es evidente que solo coincide la novela y la historia en el nombre de Juan, aunque la novelista adelante su muerte ocho años. Conviene señalar en este momento algunas obras que pudieron servir de fuente a Pilar Sinués, como son los célebres romances, cuyo género gozó de una extraordinaria aceptación en los ámbitos culturales y, fundamentalmente, literarios. Sin ánimo de ser exhaustivos, cabe recordar, el debido a Lorenzo de Sepúlveda, Resumen de la historia del rey don

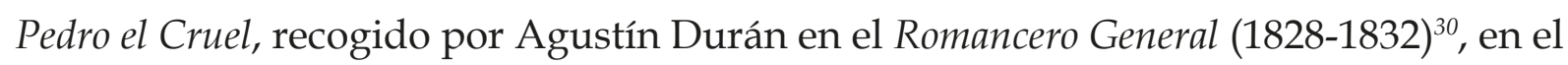
que se mencionan los asesinatos ordenados de Leonor de Guzmán y de varios de sus hijos por Pedro I, hechos que motivan la venganza de Enrique de Trastámara, al igual que sucede en La corona de perlas ${ }^{31}$. Es curioso observar también que en este romance aparece mencionada una cinta de oro recubierta de perlas y brillantes que Doña Blanca de Borbón regala a su marido, Pedro I, y que este entrega a su amante María de Padilla, pues dicho objeto reaparece en la novela del XIX que estamos analizando como prenda perteneciente a Doña Leonor, lo que pudiera corroborar esta posible fuente utilizada por Pilar Sinúes. También es posible establecer una relación con el romance titulado El Bastardo de José Joaquín de Mora ${ }^{32}$, pues este también resalta la cruel venganza de Pedro I, quien después del fallecimiento de su padre, persigue con saña la muerte de su amante, doña Leonor de Guzmán, y de sus descendientes, hasta que Enrique de Trastámara acaba con su vida en la batalla de Montiel. Igualmente, el duque de Rivas en el romance titulado El fratricidio (Tragedia de Montiel) de nuevo recrea, en forma de sueño, la enemistad insalvable entre los hijos de Alfonso $\mathrm{xI}^{33}$. Como es obvio, parece confirmarse la idea señalada en páginas anteriores, pues todo parece indicar que Pilar Sinués asienta su novela en otras obras literarias, tal como señalamos al hablar de Víctor África Bolangero.

\footnotetext{
${ }^{30}$ A. Durán, Romancero General, colección de romances castellanos anteriores al siglo XVIII, Madrid, Amarita y Aguado, 1828-1832, 5 vols. La segunda edición, aumentada, se publicó en la «Biblioteca de Autores Españoles» bajo el título Romancero General, colección de romances castellanos anteriores al siglo XVIII, recogidos, ordenados, clasificados y anotados por..., Madrid, M. Rivadeneyra, 1849 y 1851, 2 vols. En el presente trabajo citamos por el tomo II de la edición de 1861, pp. 44-45.

${ }^{31}$ En el romance de Sepúlveda el carácter cruel y sanguinario de Pedro I se contrapone a la equidad de Enrique II. En dicho romance encontramos convenientemente enumeradas las distintas víctimas ajusticiadas por orden del rey y que motivan la rebelión de Enrique de Trastámara contra su hermanastro: «[...] Mató a veinte jurados,/ otros muchos caballeros,/y a Don Fadrique, su hermano, / a Don Diego y a don Juan,/ niños, sus propios hermanos/[...] También degolló a Sancho,/ y a don Tello y Don Fadrique,/ sus hermanos son llamados/ Doña Leonor de Guzmán / también murió por su mano», A. Durán, ob. cit., pp. 45-46.

32 J. J. de Mora, Leyendas españolas, París, Librería de Vicente Salvá, 1840, Cádiz, 1840. En el presente trabajo utilizamos la edición preparada por Salvador García Castañeda y Alberto Romero Ferrer, José Joaquín de Mora. Leyendas españolas, Sevilla, Fundación José Manuel Lara, «Clásicos Andaluces», 2011, pp. 221-241.
}

${ }^{33}$ A. Saavedra, duque de Rivas, Romances históricos, Madrid, Lalama, 1840. En el presente trabajo citamos por Obras Completas. Poesías, J. Campos (ed.), Madrid, Atlas, BAE, 1957, pp. 323-327. 
En esta primera parte Pilar Sinués emplea alguno de los recursos más típicos del género, como es, por ejemplo, la utilización de prendas u objetos que faciliten el reconocimiento posterior o sirvan de salvoconducto a un determinado personaje. Así sucede, por ejemplo, con la corona de perlas que Enrique II, bajo el disfraz de Floristán, entrega a Berenguela como prueba de amor y que le servirá a la pobre enajenada para que los soldados le abran las puertas de la fortaleza y llegar así ante la presencia de su amado. Igualmente, una cinta de seda negra, con un pergamino, enrollada al cuello de Berenguela cuando el conde de Carrión la entrega para su cuidado a una humilde mujer llamada Urraca, jugará también un papel decisivo, pues el mencionado personaje tiene orden de no entregar a la niña hasta que llegue algún caballero con un pergamino igual al que lleva Berenguela, recurso este que reaparece en la segunda parte de La corona de perlas, pues la existencia de una mancha rosada de nacimiento en la piel de un costado es la prueba evidente de la consanguinidad de Enrique, Sancho y Berenguela, pues todos los descendientes de Leonor de Guzmán heredan esta marca de su madre. Es una prueba irrefutable que todos tendrán que aceptar.

La segunda parte, mucho más centrada si cabe en la ficción amorosa, en el drama con el que concluye la primera parte, nos sitúa trece meses más tarde, en el 14 de marzo de 1852, cuando Enrique II, llamado en la novela el Dadivoso, se encuentra junto a su esposa, doña Juana Manuel, en el alcázar de Toledo. Se describe la alegría que envuelve a la ciudad en contraposición con el miedo y terror experimentados en la época de Pedro i y se recrea una escena en la que los reyes de Castilla reciben a los embajadores de las naciones aliadas y a todos los enviados de las ciudades de su reino que todavía no habían podido felicitarles por su advenimiento. Pilar Sinués describe con trazos rápidos y ágiles la decoración del salón de Embajadores, las vestimentas de los personajes de la nobleza o de escuderos, pajes y donceles que con sus laúdes armonizan la velada y dulcifican las fisonomías de los propios reyes. Solo como botón de muestra, incluimos una de las numerosas descripciones que de estos personajes nos ofrece la novelista:

Enrique II recibió a los cortesanos con su grata y benévola sonrisa, a pesar de su tardanza; estaba sentado en el solio, y vestía un riquísimo traje de ceremonia; su túnica de púrpura, larga hasta la garganta de sus pequeños pies, calzados con borceguíes de brocado, bordados de oro, estaba bordada igualmente en su derredor de riquísima pedrería, y sujeta con un ceñidor de oro; llevaba el manto real prendido en el hombro derecho con un broche de diamantes, y su corona era de una riqueza deslumbradora.

Sentada junto a Enrique II estaba su esposa, vestida con un suntuoso traje de seda y oro, y recogidos sus rubios cabellos en una redecilla de corales, que remataba, junto a la frente, en una corona de oro y pedrería ${ }^{34}$.

\footnotetext{
${ }^{34}$ P. Sinués, La corona de perlas, ob. cit., p. 155.
} 
Pilar Sinués, en ocasiones, se dirige directamente al lector, para aclarar algún punto o hecho ignorado, y de esta forma situarle correctamente frente a la historia que está narrando ${ }^{35}$. Al igual que la escritora se demora en el retrato de los principales personajes, aspecto ya evidente en la descripción de aquellos que intervienen en la primera parte, apunta sus principales cualidades y muestra sus sentimientos dominantes, aquellos que condicionan su conducta. Enrique is se define en primer lugar por su ambición por reinar y por su inquebrantable amor por Berenguela, pues a pesar de que en un primer momento la abandone para cumplir con su deber como rey de Castilla, en cuanto esta se presenta en palacio, el amor renace con total intensidad. Ello le hace rechazar la revelación del conde de Carrión cuando le indica que Berenguela es su hermana, pues la naturaleza de su pasión es tal que «nada hay en el mundo capaz de apagarla. Ella es la única mujer que ha despertado mis pasiones dormidas...» ${ }^{36}$. Su corazón noble se extravía por la fuerza de la pasión amorosa, de ahí que colérico e irritado emprenda medidas violentas contra el mencionado conde de Carrión por ser portador de tan nefastas noticias y contra Sancho, pues al descubrirlo velando el sueño de la herida Berenguela, en vez de confiar en las palabras del conde de Carrión al señalarle que también es hermano suyo, los celos le impelen a empuñar su espada contra él. Cabe hacer notar que Pilar Sinués traza la psicología de sus personajes con acierto, pues no son individuos de una sola pieza, sino que muestran sus espíritus movidos por las circunstancias y las emociones, determinando estas, en ocasiones, una conducta contradictoria. Tratamiento que se aprecia también a la hora de presentarnos a doña Juana Manuel y al mencionado Sancho. La primera es calificada de bondadosa, noble, sincera y piadosa, pero también orgullosa al sentirse herida al descubrir el amor de su esposo por la joven Berenguela, un personaje de ficción magnánimo, pues no duda en aceptar la verdad revelada por el conde de Carrión y actuar, a partir de ese momento, de acuerdo a las cualidades morales que la definen. Sancho es asimismo un personaje movido por sentimientos contradictorios hacia su hermano Enrique, pues goza de una entrañable amistad cuando aún desconocen su parentesco y, una vez descubierto, Sancho envidia la fortuna de este al haber recibido el amor que sus padres le negaron a él, obligados por el noble fin de preservar su vida, y por haber estado presente en el momento en que ambos fallecieron, celos que van creciendo gradualmente al conocer que Enrique il es su rival amoroso, el causante de que Berenguela no acepte sus palabras de amor, sin que ello impida que consagre su vida a honrar ese sentimiento:

\footnotetext{
${ }^{35}$ Así, por ejemplo, en medio de la descripción de la ceremonia que se desarrolla en el salón de Embajadores, P. Sinués ofrece la historia de la reina doña Juana Manuel desde que, por razones de estado, se casa con Enrique II y concluye de esta forma: «Perdónesenos esta digresión, necesaria para dar a conocer algún tanto a la Reina de Castilla en el momento de presentarla a nuestros lectores, y volvamos a ocuparnos de la cámara real», La corona de perlas, ob. cit., p. 158.
}

${ }^{36}$ Ibidem, p. 169. 
- ¡Ah, maldición sobre ti, Enrique! Gritó levantándose con rabia el infeliz D. Sancho: ¡para ti fueron las últimas caricias de mi padre! ¡para ti también las últimas de mi madre, y el amor de entrambos mientras vivieron! ipara ti el cariño de Berenguela, su vida y su razón, porque ambas cosas pierde por ti!... ¡maldito seas! ${ }^{37}$

Sancho además se define por su valentía y lealtad, al conde de Carrión que le ha criado como un hijo y al propio Enrique II, pues en el enfrentamiento armado que se produce en la habitación en la que descansa la infanta Berenguela, Sancho solo emplea la espada para defenderse, incapaz de atacar a Enrique por ser, además de su hermano, su rey.

Los personajes que no albergan cualidades negativas son Berenguela y el conde de Carrión. La primera, trazada con un único rasgo caracterizador, su amor por Floristán, que le lleva a la enajenación mental y a la muerte, cuando el conde de Carrión, con tal de impedir que Enrique cometa incesto, no duda en hacerle beber el veneno que contiene la corona de perlas que este le entrega a Berenguela como prueba de amor. El conde de Carrión es el prototipo por excelencia del héroe romántico, un hombre leal a sus reyes, un noble bondadoso que protegerá a los dos últimos infantes de Alfonso xI de su incierta suerte, valiente en la lucha al lado de Enrique de Trastámara, tremendamente generoso al poner su riqueza en sus manos cuando este se rebela contra Pedro i para vengar el asesinato de su madre, tal como el propio Enrique I reconoce, a pesar de la ira que le embarga al oponer el conde a su deseo de mantener a Berenguela a su lado, en la conversación que mantiene con Nuño Sandoval, enemigo del conde de Carrión, D. Álvaro Garcés, quien acusa a este de estar movido por la ambición:

- Sin embargo, Nuño, el Conde era el mejor amigo de mi padre, y tiene dadas pruebas de que no es ambicioso, como tú lo llamas; cuando murió D. Alonso, en vez de hacerse partidario de D. Pedro para medrar, vino a mis tercios y defendió bravamente mi causa, aunque yo errante, nada podía darle; más de una vez he tenido que recurrir a sus rentas, en medio de mi escasez, y su bolsillo y su vida han sido siempre del bastardo desvalido ${ }^{38}$.

Es un hombre capaz de llevar a cabo el envenenamiento de Berenguela porque el honor, la honra, está para él por encima de cualquier otra cuestión y consideración, le ha obligado a mantener siempre ocultos sus profundos sentimientos amorosos hacia Leonor de Guzmán, a pesar del dolor que esto le ocasiona a lo largo de los más de veinte años que estuvo al servicio del rey Alfonso xI y su amante, de ahí que en el texto se le defina, en alguna ocasión, como un auténtico mártir de amor. Así lo denomina Sancho cuando el conde de Carrión le confiesa el infinito amor que desde su más tierna

\footnotetext{
${ }^{37}$ Ibidem, p. 139.

${ }^{38}$ Ibidem, p. 164. 
infancia profesaba por Leonor — «Pobre mártir!»39. D. Álvaro Garcés se define como un auténtico descendiente del amor cortés ensalzado por trovadores y poetas, del amante platónico que puebla, singularmente, la literatura del Renacimiento, del amor al que no se puede renunciar, pues es imprescindible para continuar viviendo aunque se desee la muerte para acabar con el sufrimiento de la no correspondencia. Un amor que, en el caso del conde de Carrión, se conforma con estar cerca de su amada, viendo su felicidad al lado del Alfonso xI, sufriendo en silencio su amor no correspondido, desde que se inician los amores entre Leonor y el rey:

[...] desde aquella fatal noche, ni una sola dejé de acompañar a vuestro padre a ver a Leonor, ni un solo día pasó sin que sintiese crecer en mi pecho la ardiente hoguera de mi funesto amor; supe, sin embargo, encerrarlo en lo más recóndito de mi corazón, porque quería al Rey con toda mi alma, y no me era posible causarle el más pequeño dolor, y porque anhelaba conservar el único bien que me hacía soportar la vida: el amargo placer de ver a Leonor todos los días, aunque fuese en los brazos de otro; de este modo me hice yo mártir de mi propio corazón, y ninguno de los que sacrificaron los inicuos Emperadores de la antigua Roma sufrió tormentos comparables a los míos ${ }^{40}$.

En La corona de perlas, especialmente en su segunda parte, los elementos folletinescos se imponen al componente histórico, que apenas hace acto de presencia en ella. A Pilar Sinués le interesa acrecentar el carácter trágico del argumento, de ahí que retuerza o fuerce el argumento con la inclusión de las reacciones violentas que enfrentan a los principales personajes masculinos y con el poco justificado desenlace. No olvidemos que Enrique II está dispuesto a mantenerse en un plano totalmente platónico, conformándose, en situación paralela a la experimentada por el conde de Carrión, con gozar de la presencia de Berenguela. No obstante, es justo reconocer la dificultad de ofrecer un desenlace que satisfaga a lectores, pues a pesar de las buenas intenciones de los personajes involucrados, que renuncian a un amor carnal, los afectos del mismo son inamovibles: Berenguela enamorada sin remisión de Enrique II y este y Sancho de la mencionada joven con idéntica pasión. De ahí que la escritora condene a muerte a Berenguela, porque su muerte reviste a la historia de un mayor dramatismo, ya que ninguno de los personajes volverá a gozar de una felicidad plena. Sancho y Juana morirán de melancolía, Sancho por no poder soportar la muerte de Berenguela, $\mathrm{y}$, seis meses más tarde de su fallecimiento, el mismo mal aqueja a la reina Juana Manuel, que parece añorar a Sancho. El rey ordena colocar el cadáver de su esposa al lado de la tumba de Sancho, pues Dios «le advirtió en sueños que las purísimas almas de la Reina y del Infante moraban juntas en el cielo» ${ }^{41}$. A raíz de todos estos hechos luctuosos, Enrique II de Castilla no volverá a ser feliz, ya que ni siquiera «el amor de

\footnotetext{
${ }^{39}$ Ibidem, p. 123.

${ }^{40}$ Ibidem, p. 119.

${ }^{41}$ Ibidem, p. 208.
} 
sus hijos pudo consolar el hondo pesar que le devoraba el corazón» ${ }^{42}$.

Es evidente que Pilar Sinués en La corona de perlas da muestra de sus dotes de novelista, de su habilidad para hilvanar una melodramática historia de amor que se sustenta en datos y personajes históricos, elementos convenientemente seleccionados para alcanzar su principal objetivo: dar verosimilitud a la enrevesada, interesante y trágica narración que ofrece a sus lectores.

\section{BibliografíA}

BöHl De Faber, C., La Gaviota, E. Rubio Cremades (ed.), Madrid, Espasa Calpe, 1991. Bolangero, V. A., Don Pedro I de Castilla o El grito de la venganza. Novela histórica original, Madrid, Repullés, 1850.

- Fernando IV de Castilla o dos muertos a un tiempo. Novela histórica del siglo XIV, Madrid, Márquez, 1850.

Alfonso el Onceno o quince años después. Novela histórica. Continuación de Fernando IV de Castilla, Madrid, Librería de Sánchez Rubio, Imprenta de Miguel G. González, 1850.

Establier Pérez, H., «La novela histórica femenina en los albores del Romanticismo (1814-1833): creación original y adaptación de la literatura francesa en España», RILCE, 31, 1 (2015), pp. 171-199.

, «Historia, ideología y perspectiva de género en la España del siglo xIX: el “ciclo" de leyendas históricas de María del Pilar Sinués de Marco (1855-1857)», Hispanófila (en prensa).

FERrERAs, J. I., Los orígenes de la novela decimonónica. 1800-1830, Madrid, Taurus, 1973.

Gómez De Avellaneda, G., Obras, J. M. Castro y Calvo, Madrid, Atlas, 1974-1978, 2 vols. GonzÁlez SANZ, A. «El uso de la historia en la poesía romántica femenina: el caso de María del Pilar Sinués (1835-1893)», en S. Boadas, F. E. Chávez y D. García Vicens (coords.), La tinta en la clepsidra: fuentes, historia y tradición en la literatura hispánica, Barcelona, PPU, 2012, pp. 223-230.

«Domesticar la escritura. Profesionalización y moral burguesa en la obra pedagógica de Pilar Sinués (1835-1893)», Revista de Escritoras Ibéricas, 1 (2013), pp. 223-230.

DuRÁN, A., Romancero General, colección de romances castellanos anteriores al siglo XVIII, Madrid, Amarita y Aguado, 1828-1832, 5 vols.

Hibbs-Lissorgues, S., «Escritoras españolas entre el deber y el deseo: Faustina Sáez de Melgar (1834-1895), Pilar Sinués de Marco (1835-1893) y Antonia Rodríguez de Ureta», en P. Fernández y M. L. Ortega (eds.), La mujer de letras o la letraherida:

\footnotetext{
${ }^{42}$ Ibidem, p. 208.
} 
discursos y representaciones sobre la mujer escritora en el siglo XIX, Madrid, CSIC, 2008, pp. 325-343.

López De Ayala, P., En el nombre de Dios, amén, comienza la crónica del Rey Don Pedro, fijo del rey don Alfonso, Onceno (I) de este nombre en Castilla, en Crónicas de los Reyes de Castilla, C. Rosell (ed.), Madrid, Rivadeneyra, Editor, 1875.

MorA, J. J., Leyendas españolas, París, Librería de Vicente Salvá, 1840, Cádiz, 1840.

Leyendas españolas, S. García Castañeda y A. Romero Ferrer (eds.), Sevilla, Fundación José Manuel Lara, «Clásicos Andaluces», 2011.

Palau Dulcet, A., Manual del librero hispano-americano, Barcelona, Palau Dulcet, t. II, 1949.

Peers, E. A., Historia del movimiento romántico español, Madrid, Gredos, 2 vols., 1973 (2a ed.).

Simón Palmer, C., «Pilar Sinués», en Escritoras españolas del siglo XIX. Manual biobibliográfico, Madrid, Castalia, 1991, pp. 650-671.

SINUÉs, P., Luz de luna, Revista Española de Ambos Mundos, t. III (1855), pp. 634-661; Luz de luna. Leyenda histórica del siglo XV, Zaragoza, Imprenta de Ramón León, 1855; Luz de luna, en Amor y llanto. Colección de novelas históricas originales, Madrid, Imprenta de T. Núñez Amor, 1857, pp. 209-257.

, El Ángel de la Muerte (leyenda histórica), en Cantos de mi lira. Colección de leyendas en verso, Madrid, Imprenta de Tomás Núñez Amor, 1857, pp. 17-111.

, Las dos sultanas. Leyenda árabe, en Cantos de mi lira, Colección de leyendas en verso, Madrid, Imprenta de Tomás Núñez Amor, 1857, pp. 181-259.

- La diadema de perlas. Novela histórica original, en Amor y llanto. Colección de novelas históricas originales, Madrid, Imprenta de T. Núñez Amor, 1857, pp. 261-307. , La corona de sangre, en Amor y llanto. Colección de novelas históricas originales, Madrid, Imprenta de T. Núñez Amor, 1857, pp. 5-90.

, La hermana de Velázquez, en Amor y Llanto. Colección de novelas históricas originales, Madrid, Imprenta de T. Núñez Amor, 1857, pp. 313-421.

, iiPobre Ana!! Leyenda histórica, Madrid, Imprenta de Juan Antonio García, 1861. , Dos venganzas. Novela histórica, Madrid, Imprenta Española, 1862.

, Dona Urraca Queen of Leon and Castile. An historical romance of the Middle Ages. Traslated fron Spanish by Reginal Huth, Bath, Wilkinson Bros., 1890.

Romero Tobar, L., «María Pilar Sinués, de la provincia a la capital del reino», Arbor, 190-767 (mayo-junio 2014), pp. 1-9.

Rubio CRemades, E., «La novela histórica en el romanticismo español», en Historia de la literatura española. Siglo XIX (I), Madrid, Espasa Calpe, 1996, pp. 610-642.

SaAvedra, A., DUQue de Rivas, Romances históricos, Madrid, Lalama, 1840. Duque de Rivas, Obras Completas. Poesías, J. Campos (ed.), Madrid, Atlas, BAE, 1957. 
SÁnchez Llama, I., «El 'varonil' realismo y la cultura oficial de la Restauración en el fin de siglo peninsular: el caso de María Pilar Sinués de Marco (1835-1893)», Letras Peninsulares, 12, 1 (1999), pp. 37-64.

«María Pilar Sinués de Marco y la cultura oficial peninsular del siglo XIX: del neocatolicismo a la estética realista», Revista Canadiense de Estudios Hispánicos, XXIII, 2 (1999), pp. 271-288.

, Galería de escritoras isabelinas. La prensa periódica entre 1833 y 1895, Madrid, Cátedra, 2000.

, Antología de la prensa periódica isabelina escrita por mujeres, Cádiz, Universidad, 2001.

Vadeón Baruque, J., Pedro i y Enrique de Trastamara. ¿La primera guerra civil española?, Madrid, Aguilar, 2003.

, Los Trastámaras: El triunfo de una dinastía bastarda, Madrid, Temas de España, 2001.

Wallace, D., The Woman`s Historical Novel, Houndmills, Basingstoke, Palgrave Macmillan, 2005.

Wallach Scott, J., Género e historia, México, FCE y Universidad Autónoma de la Ciudad de México, 2008. 